\title{
Highly versus Normally Attractive Person in Picture Reviews
}

\author{
Rui Wang, Baoying Feng, Siyun Chen \\ School of Management, Jinan University, Guangzhou, China \\ Email: byfeng94@foxmail.com
}

How to cite this paper: Wang, R., Feng, B.Y. and Chen, S.Y. (2019) Highly versus Normally Attractive Person in Picture Reviews. Journal of Service Science and Management, 12, 371-381.

https://doi.org/10.4236/jssm.2019.123025

Received: February 21, 2019

Accepted: April 8, 2019

Published: April 11, 2019

Copyright $\odot 2019$ by author(s) and Scientific Research Publishing Inc. This work is licensed under the Creative Commons Attribution International License (CC BY 4.0).

http://creativecommons.org/licenses/by/4.0/

(c) (i) Open Access

\begin{abstract}
This research explored the impact of person's physical attractiveness in the picture reviews on women's clothing purchase intention. The results showed that the physical attractiveness of the person in the picture reviews significantly affected the purchase intention of consumers, and the highly attractive person (HAP) could promote the purchase behavior of consumers. Body image was a mediator in the relationship between person's physical attractiveness in picture reviews and consumers' purchase intention, that is, people's physical attractiveness indirectly influenced consumers' purchase intention through body image. Finally, the influence of person's physical attractiveness on consumers' purchase intention was moderated by perceived similarity. When the consumers perceived that the people in the pictures were similar, HAP would promote their buying behavior. However, when the consumers perceived that the people in the pictures were dissimilar, HAP would reduce their buying behavior.
\end{abstract}

\section{Keywords}

Picture Reviews, Physical Attractiveness, Body Image, Perceived Similarity

\section{Introduction}

Online reviews, as one of the manifestations of online word-of-mouth, are not only an important way for people to obtain product information, but also affect consumers' purchasing behavior. In recent years, the role of online reviews has attracted great attention from the academic circle. Scholars have explored the influence of textual reviews on consumers' psychology and behavior, mainly focusing on the quality of reviews [1] [2], the number of reviews [3] [4], and the reviews' valence [5] [6]. In addition, scholars' research had also found different effects of picture reviews and textual reviews in specific situations. Yang and Zhu 
(2016) found that consumers with high purchase feasibility were more influenced by picture reviews than textual reviews [7]. Zhang and Li (2016) found that picture reviews of search products can effectively enhance the usefulness of online comments [8]. Lin, Lu and Song (2017) found that the picture reviews of sensory products had a greater impact on consumers' purchase intention than the textual reviews [9]. Previous researches had deeply discussed the influences of textual reviews on consumers, and compared the different functions of picture reviews and textual reviews, but rarely discussed the influence of the characteristics of picture reviews on consumers' purchase decisions and their psychological mechanism.

Clothing belongs to the type of sensory products, but consumers can't direct contact with the product itself in the online shopping environment. In addition, textual online reviews cannot clearly describe product information and consumer experience, so picture reviews are used to provide consumers with product information to make up for the deficiency of textual reviews [10]. This research will explore the influence of the physical attractiveness of the people in the online picture reviews on the psychology and the clothing purchase decision of female consumers, so as to provide suggestions for the clothing sellers in the e-commerce platform to manage the reviews' information.

In the following part of this paper, three hypotheses are proposed through theoretical derivation. Then, two experiments were conducted to verify the hypothesis. Finally, we will discuss the research results and propose future research prospects.

\section{Hypothesis}

Physical attractiveness is a specific image that enables one to experience pleasure, which contains many contents, such as appearance, body shape, clothing, hairstyle [11]. Research on product aesthetics has proved that visually appealing products can trigger consumers' positive responses on their emotion, cognitive and even neural level [12] [13]. Scholars found that highly attractive models can bring better results to appearance-related products (e.g., shampoo, deodorant, underwear), and highly attractive models were more professional than normally attractive models, so as to improve the advertising effect of enhancing beauty products (e.g. lipstick, jewelry) [14] [15].

When shopping online, consumers are more likely to be attracted by pictures because they cannot have direct contact with products, and transfer the positive emotions caused by pictures to products and brands [16] [17]. As a result, picture reviews that include highly attractive person (HAP) will trigger consumers' feelings of pleasure and positive emotions and ultimately increase their willingness to buy. Therefore,

H1: Compared with the normally attractive person (NAP), the picture reviews that include HAP can arouse women's higher clothing purchase intention. 
Body image refers to the mental image formed by individuals of their own weight, body shape and body [18]. In the online shopping environment, consumers cannot directly appreciate, touch and try on clothing products like the traditional shopping process. They can only imagine their shopping experience in their mind based on the existing information and form a general image. Clothing is called "visible self" and "second skin" of human beings [19].

When shopping online for clothes, consumers' brains will form images related to their bodies, namely body image, and judge the clothing products. At the same time, consumers' mental image of their bodies will directly affect their feelings and emotions, and then they will transfer these feelings and emotions to clothing products. When consumers' body image is positive enough, it will promote their buying behavior. Conversely, when consumers' body image is negative, their buying behavior will be reduced. That is to say, as a kind of product information, the physical attractiveness of the person in the picture reviews will affect the consumers' body image and further influence their buying behavior. Therefore,

H2: Body image was a mediator in the relationship between person's physical attractiveness in picture reviews and consumers purchase intention.

The state body image of an individual is easily influenced by the mass media, for the reason that the individual will compare herself with the model image presented by the media and make a comparative evaluation of her own body [20] [21], which is related to social comparison in the field of appearance.

Perceived similarity refers to the similarity between the commentator's characteristics and the reader's own [22] [23]. According to the selective accessibility (SA) model proposed by Mussweiler (2003), the effect of information comparison is the result of the hypothesis testing process [24]. If the initial evaluation results show that they are similar to the object of comparison, the judge will conduct a similarity test. On the contrary, if the initial evaluation indicates that they are different from the object of comparison, the judge will carry out the dissimilarity test. Similarity test produces assimilation effect, while dissimilarity test produces contrast effect [24] [25] [26].

Therefore, when consumers are faced with pictures reviews that contain characters similar to themselves, HAP will trigger consumers' more positive body image (assimilation effect), thus promoting consumers' purchase intention. When consumers are faced with pictures reviews containing figures that are not similar to them, HAP will cause more negative body image (contrast effect) for consumers, thus reducing consumers' purchase intention. Therefore,

H3: The influence of person's physical attractiveness in picture reviews on consumer's purchase intention was moderated by perceived similarity.

To test our hypothesis, we conducted two experiments in which participants were asked to rate their attitudes. In study 1 , striped skirt was used as the experimental material to manipulate the person's physical attractiveness, and to test 
the influence of physical attractiveness on consumers' purchase intention and the mediating effect of body image. In study 2, the striped skirt was also used as the experimental material to manipulate the physical attractiveness and perceived similarity of the persons, and to test the interactive influence of the physical attractiveness and perceived similarity on the purchase intention.

\section{Study 1}

The study consisted of a 2 (physical attractiveness: NAP vs. HAP) between-subjects experimental design, to test whether HAP in the picture reviews would trigger a higher purchase intention of female consumers, and to explore the mediating role of body image, namely to verify whether hypothesis $\mathrm{H} 1$ and $\mathrm{H} 2$ are true.

\subsection{Pretest}

In order to verify the applicability of the manipulated material for physical attractiveness, we conducted a pretest. This study selects the striped skirt as the experimental material. We selected a picture displayed by consumers in the product reviews as the prototype and processed the picture with reference to previous experimental studies [14] [27], then obtained a pair of pictures with NAP or HAP, as shown in Figure 1.

This study focused on the effect of the physical attractiveness of the people in the picture reviews on female consumers, and the selected experimental materials were also targeted at female consumers, so only female were invited to participate in the study [15]. Sixty-six female students who volunteered to take part in the study for a fee were randomly divided into two groups and asked to look at either picture include NAP or HAP. After viewing the picture material, the

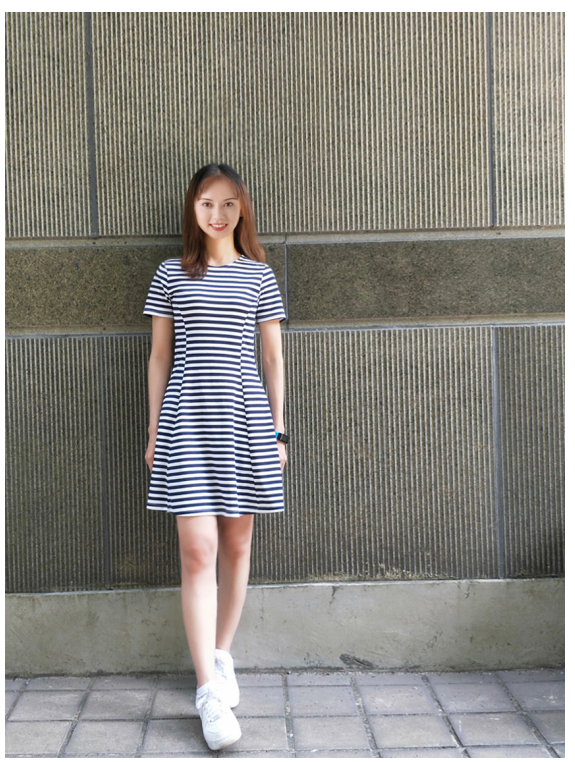

(a)

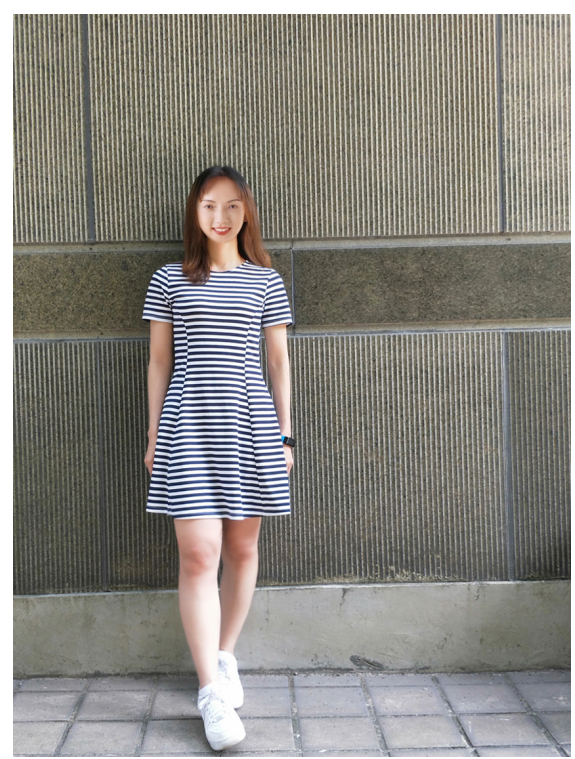

(b)

Figure 1. Experimental material. (a) HAP; (b) NAP. 
subjects were asked to complete the physical attractiveness scale [28]. The subjects in the HAP group rated the physical attractiveness of the characters $(\mathrm{M}=$ $5.06, \mathrm{SD}=0.54)$ significantly higher than those in the NAP group $(\mathrm{M}=4.11, \mathrm{SD}=$ $0.75, t=-5.953, p<0.001)$, indicating that it was appropriate to use the pictures as manipulation materials for the physical attractiveness.

\subsection{Subjects and Procedure}

The main study consisted of 110 female students who volunteered to participate in the study for the experimental reward. Their average age was 20.95 years (SD = 2.27). All of them had the experience of buying clothes online and were paid 5 RMB after the experiment.

The experimental process was completed on the mobile phone screen. We imitate the product page of the e-commerce platform to display pictures. First, show the pictures of the pure clothes (excluding people) of the striped skirt to the participants. Subsequently, the subjects were randomly assigned to any of the 2 (physical attractiveness: NAP vs. HAP) groups, in which the NAP group viewed the picture reviews containing the NAP, and the HAP group watched the picture reviews with HAP. In addition to the people in the picture commentary, the other information (e.g. price, size, picture size, etc.) that the two groups of subjects saw were identical. After viewing the picture reviews, the subjects were asked to rate the physical attractiveness of the figures in the picture reviews [28], complete the body image state scale and purchase intention scale [29] [30]. All variables were scored by a seven-point Likert scale. Finally, the participants were asked to answer the gender, age, and awareness of the experimental intent, then the experiment was over and rewarded.

\subsection{Results}

Manipulation Checks. Female subjects in the HAP group rated the physical attractiveness of the figure in the picture higher than those in the NAP group $\left(\mathrm{M}_{\mathrm{NAP}}=4.12, \mathrm{M}_{\mathrm{HAP}}=5.10, \mathrm{t}=-5.649, \mathrm{p}<0.001\right)$, indicating that the manipulation of physical attractiveness in this experiment was successful.

Purchase Intention. Women in the HAP group had higher purchase intention than those in the NAP group $\left(\mathrm{M}_{\mathrm{NAP}}=2.96, \mathrm{SD}_{\mathrm{NAP}}=1.08, \mathrm{M}_{\mathrm{HAP}}=4.03, \mathrm{SD}_{\mathrm{HAP}}=\right.$ $1.05, t=-5.253, p<0.001)$. That is, the main effect of physical attractiveness is significant, and hypothesis $\mathrm{H} 1$ is verified.

Mediation Analysis. We used bootstrapping with repeated extraction of 5000 samples to test our process model (model 4). Results revealed that the indirect effect through the body image was significant (effect $=0.63, \mathrm{LLCI}=0.39, \mathrm{ULCI}=$ 0.92 ), showed that body image had a significant mediating effect. The direct effect for physical attractiveness on women's purchase intention remained significant $(\mathrm{LLCI}=0.06$, ULCI $=0.65$ ). Therefore, body image plays a partial mediating role in the influence of characters' physical attractiveness on consumers' purchase intention, assuming that $\mathrm{H} 2$ is supported by data. 
Discussion. The results of study 1 verified the hypothesis H1, that person's physical attractiveness in picture reviews would influence consumers' purchase intention. Viewing picture reviews of people with high physical attractiveness tended to boost consumer' buying behavior, whereas viewing picture reviews of people with average physical attractiveness had the opposite effect. At the same time, this study also confirmed the mediating effect of body image, supporting hypothesis H2. Picture reviews with HAP promote consumers' purchase intention by improving their body image, while picture reviews with NAP do the opposite.

\section{Study 2}

The second study was a 2 (physical attractiveness: NAP vs. HAP) $\times 2$ (perceived similarity: dissimilar vs. similar) between-subjects experimental design, to test the moderating effect of perceived similarity on the effect of person's physical attractiveness in picture reviews on consumers' purchase intention, namely to verify whether hypothesis $\mathrm{H} 3$ is true.

\subsection{Pretest}

In order to verify whether the manipulation method of perceived similarity is applicable, we conducted another pretest. This experiment uses the pictures of study las the experimental material. In the pretest, 100 female college students who volunteered to participate in the study were randomly assigned to one of 2 (physical attractiveness: NAP vs. HAP) $\times 2$ (perceived similarity: dissimilar vs. similar) groups. They were asked to look at pictures of people who were highly or normally attractive. Regarding the manipulation of perceived similarity, in the similar group, we told subjects that the clothing size of the figure in the picture was the same as that of the subject, while the dissimilar group did not provide relevant information [23]. After viewing the picture materials, the subjects were required to complete the physical attractiveness scale [28] and perceived similarity scale [31].

A 2 (physical attractiveness: NAP vs. HAP) $\times 2$ (perceived similarity: dissimilar vs. similar) ANOVA with physical attractiveness as the dependent variable indicated the main effect of physical attractiveness $\left(\mathrm{M}_{\mathrm{NAP}}=4.19, \mathrm{SD}_{\mathrm{NAP}}=0.67\right.$, $\left.\mathrm{M}_{\mathrm{HAP}}=4.98, \mathrm{SD}_{\mathrm{HAP}}=0.59, \mathrm{~F}(1,96)=39.158, \mathrm{p}<0.001\right)$. Meanwhile, the main effect of perceived similarity $(\mathrm{F}(1,96)=1.458, \mathrm{p}>0.05)$ and the interaction effect of physical attractiveness and perceived similarity $(\mathrm{F}(1,96)=0.173, \mathrm{p}>$ 0.05 ) were not significant. These results suggest that it is appropriate to use these pictures as manipulation material for physical attractiveness.

A 2 (physical attractiveness: NAP vs. HAP) $\times 2$ (perceived similarity: dissimilar vs. similar) ANOVA with perceived similarity as the dependent variable indicated the main effect of perceived similarity $\left(\mathrm{M}_{\text {dissimilar }}=3.63, \mathrm{SD}_{\text {dissimilar }}=1.03\right.$, $\left.\mathrm{M}_{\text {similar }}=4.29, \mathrm{SD}_{\text {similar }}=1.18, \mathrm{~F}(1,96)=8.750, \mathrm{p}<0.01\right)$. Meanwhile, the main effect of physical attractiveness $(F(1,96)=0.188, p>0.05)$ and the interaction 
effect of physical attractiveness and perceived similarity $(\mathrm{F}(1,96)=0.371, \mathrm{p}>$ 0.05 ) were not significant. These results suggest that it is appropriate to use these pictures as manipulation material for physical attractiveness. To sum up, it is appropriate to manipulate the perceived similarity of subjects through clothing size.

\subsection{Subjects and Procedure}

148 female undergrads were invited to participate in the experiment and were paid after the experiment. Their average age was 21.85 years $(\mathrm{SD}=3.15)$, and their average BMI was 21.31 (SD = 2.65). All of them had the experience of buying clothes online, and they were paid $5 \mathrm{RMB}$ after the experiment.

We simulated the product page of taobao.com to display the pictures, and the subjects completed the questions set in this experiment through the link of the questionnaire. First, the subjects were asked about their height, weight and clothing size, and were presented with the pictures of the pure clothes (excluding people) of the striped skirt. Afterwards, the subjects were randomly assigned to either 2 (physical attractiveness: NAP vs. HAP) $\times 2$ (perceived similarity: dissimilar vs. similar) groups to read the picture reviews. The manipulation of physical attractiveness and perceived similarity was the same as that in the pretest. Except for the person and clothing size information in the picture reviews, the other information of the four groups was exactly the same. After viewing the picture reviews, the subjects were asked to rate the physical attractiveness of the characters in the picture reviews [28], and completed the body image state scale, purchase intention scale and perceived similarity scale [29] [30] [31]. In addition, the usefulness and credibility of reviews were measured as control variables [32] [33]. All variables were scored using a seven-point Likert scale. Finally, the participants were asked to answer the gender, age, and awareness of the experimental intent, and then the experiment was over and rewarded.

\subsection{Results}

Manipulation Checks. A 2 (physical attractiveness: NAP vs. HAP) $\times 2$ (perceived similarity: dissimilar vs. similar) ANOVA showed that the manipulation of physical attractiveness in this experiment was effective $\left(\mathrm{M}_{\mathrm{NAP}}=4.26, \mathrm{M}_{\mathrm{HAP}}=\right.$ 4.93, $\mathrm{F}(1,144)=11.430, \mathrm{p}<0.001)$. Similarly, the manipulation of perceived similarity in this experiment was also successful $\left(\mathrm{M}_{\text {dissimilar }}=3.54, \mathrm{M}_{\text {similar }}=4.37\right.$, $\mathrm{F}(1,144)=14.075, \mathrm{p}<0.001)$. In addition, the results of two-factor ANOVA with the usefulness and the credibility as dependent variables showed that the main effect of the physical attractiveness, the main effect of the perceived similarity and the interaction effect between them were not significant, excluding the influence of experimental materials on the usefulness and the credibility of the reviews.

Purchase Intention. A 2 (physical attractiveness: NAP vs. HAP) $\times 2$ (perceived similarity: dissimilar vs. similar) ANOVA showed that the main effect of physi- 
cal attractiveness was significant $(\mathrm{F}(1,144)=4.154, \mathrm{p}<0.05)$, the main effect of perceived similarity was also significant $(F(1,144)=14.098, p<0.001)$. Most importantly, the interaction effect between physical attractiveness and perceived similarity was significant $(\mathrm{F}(1,144)=27.301, \mathrm{p}<0.001)$.

Specifically, when subjects perceived that the characters in the pictures were similar with themselves, subjects in the group with HAP had a higher purchase intention than those in the NAP group $\left(\mathrm{M}_{\mathrm{NAP}}=3.29, \mathrm{SD}_{\mathrm{NAP}}=1.48, \mathrm{M}_{\mathrm{HAP}}=4.95\right.$, $\left.\mathrm{SD}_{\text {HAP }}=1.43, \mathrm{~F}(1,144)=22.32, \mathrm{p}<0.001\right)$. On the contrary, when the subjects perceived that the persons in the pictures were not similar with themselves, the subjects in the group with HAP had lower purchase intention than those in the group with NAP $\left(\mathrm{M}_{\mathrm{NAP}}=3.62, \mathrm{SD}_{\mathrm{NAP}}=1.31, \mathrm{M}_{\mathrm{HAP}}=2.89, \mathrm{SD}_{\mathrm{HAP}}=1.33, \mathrm{~F}(1\right.$, $144)=3.97, \mathrm{p}<0.05)$. In summary, the main effect of physical attractiveness is significant, that is, hypothesis $\mathrm{H} 1$ is verified again. The interaction effect between physical attractiveness and perceived similarity is also significant, so hypothesis $\mathrm{H} 3$ is verified.

Mediation Analysis. We used bootstrapping with repeated extraction of 5000 samples to test our process model (model 8 ). The results showed that body image had significant mediating effect $($ effect $=2.68$, LLCI $=1.95$, ULCI $=3.53$ ). Specifically, when subjects perceived that the figure in the picture was similar to themselves, the mediating effect of body image was significant (effect $=1.97$, LLCI $=1.45$, ULCI $=2.51$ ). Meanwhile, the mediating effect of body image was also significant when subjects perceived that the figure in the picture was not similar to themselves (effect $=-0.71$, LLCI $=-1.27$, ULCI $=-0.21$ ). In addition, after controlling for the mediating variable body image, the effect of the independent variable physical attractiveness on the purchase intention of the dependent variable was no longer significant. Therefore, body image plays a completely mediating role in the influence of persons' physical attractiveness and perceived similarity on consumers' purchase intention.

Discussion. The results of study 2 reaffirmed the hypothesis H1that person's physical attractiveness in picture reviews would affect the purchase intention of consumers, and the picture reviews with HAP would tend to promote the purchase behavior of consumers. Furthermore, when the female perceived that the figure in the picture was similar to her, the picture reviews containing HAP would increase her purchase intention by improving her body image. However, when female consumers perceived that the figure in the picture was not similar to them, the picture reviews containing HAP would reduce the consumers' body image and thus lead to a decrease in their purchase intention.

\section{Discussion}

This study explores the influence of the physical attractiveness of the characters in the picture reviews on e-commerce platforms on consumers' purchase intention. The first experiment proved that the picture reviews with high attractive person can promote the purchase intention of consumers, and the body image 
plays a mediating role. Study 2 proved that perceived similarity plays a moderating role in the influence of person's physical attractiveness on consumers' purchase intention. To be specific, when people in the picture are perceived to be similar, the picture reviews with HAP can promote consumers' purchase intention. When people in the picture are perceived to be dissimilar, the picture reviews with HAP would reduce consumers' purchase intention. In addition, the clothing size of the figure in the picture reviews can affect the perceived similarity of consumers. Therefore, when consumers take pictures with similar characters as reference, pictures with HAP are beneficial to clothing sales. However, when consumers refer to pictures containing dissimilar figures, the pictures with HAP are not conducive to clothing sales. Based on the above conclusions, we can provide suggestions to marketers. In general, beautiful people lead to better sales results. However, when consumers perceive that the person from picture reviews is not similar to them, beautiful persons will bring worse results to the product. Therefore, blindly pursuing beautiful picture reviews is not a good marketing method.

In addition, this study also has some deficiencies. First, the phenomenon verified in this study only exists among female consumers, and whether the same phenomenon exists in the process and decision-making of male consumers in the purchase of clothing has not been discussed. Second, this study only considers clothing size as a factor affecting consumers' perceived similarity, and does not discuss other influencing factors, such as height and weight. Third, this study has not yet explored the behavior of consumers after purchase, such as return. All these shortcomings need to be further studied in the future.

\section{Acknowledgements}

This research was funded by the National Natural Science Foundation of China (71302151), the Ministry of Education Humanities Social Science Foundation (12YJC630208), and Jinan University Key Discipline Construction Foundation (GY14011).

\section{Conflicts of Interest}

The authors declare no conflicts of interest regarding the publication of this paper.

\section{References}

[1] Park, D.H., Lee, J. and Han, I. (2007) The Effect of On-Line Consumer Reviews on Consumer Purchasing Intention: The Moderating Role of Involvement. International Journal of Electronic Commerce, 11, 125-148. https://doi.org/10.2753/JEC1086-4415110405

[2] Zhou, M., Li, P. and Mou, Y. (2015) Effects of Online Reviews on Purchase Intention of Consumers: The Mediation of Psychological Distance. Soft Science, 29, 101-104.

[3] Lu, X. and Feng, Y. (2009) The Value of the Public Praise over Network. Management World, 7, 126-132. 
[4] Zheng, C., Han, Q. and Wang, H. (2015) How Do Paid Posters' Comments Affect your Purchase Intention. Nankai Business Review, 18, 89-97.

[5] Du, X., Zhao, Z. and Cui, X. (2015) The Effect of Review Valence, New Product Types and Regulatory Focus on New Product Online Review Usefulness. Acta Psychologica Sinica, 47, 555-568. https://doi.org/10.3724/SP.J.1041.2015.00555

[6] Du, X., Ding, J., Xie, Z. and Lei, L. (2016) An Empirical Study on the Impact of Online Reviews on Consumers' Purchasing Intention. Management Review, 28, 173-183.

[7] Yang, Y. and Zhu, Y. (2016) Effects of Online Pictorial versus Verbal Reviews of Experience Product on Consumer's Judgment. Acta Psychologica Sinica, 48, 1026-1036. https://doi.org/10.3724/SP.J.1041.2016.01026

[8] Zhang, Y. and Li, Z. (2016) Analysis of the Factors that Influence Online Reviews Helpfulness: Based on the Regulating Effect of Product Type. Management Review, 28, 123-132.

[9] Lin, S., Lv, X. and Song, H. (2017) Is a Picture Worth a Thousand Words? The Effect of Pictorial Reviews and Verbal Reviews on Consumer Purchase Intention. Journal of Business Economics, 8, 59-68.

[10] Li, Q., Huang, Z. and Christianson, K. (2016) Visual Attention toward Tourism Photographs with Text: An Eye-Tracking Study. Tourism Management, 54, 243-258. https://doi.org/10.1016/j.tourman.2015.11.017

[11] Hatfield, E. (1986) Mirror, Mirror: The Importance of Looks in Everyday Life. SUNY Press, Albany, New York.

[12] Hagtvedt, H. and Patrick, V.M. (2008) Art Infusion: The Influence of Visual Art on the Perception and Evaluation of Consumer Products. Journal of Marketing Research, 45, 379-389. https://doi.org/10.1509/jmkr.45.3.379

[13] Reimann, M., Zaichkowsky, J., Neuhaus, C., Bender, T. and Weber, B. (2010) Aesthetic Package Design: A Behavioral, Neural, and Psychological Investigation. Journal of Consumer Psychology, 20, 431-441. https://doi.org/10.1016/j.jcps.2010.06.009

[14] Bower, A.B. and Landreth, S. (2001) Is Beauty Best? High versus Normally Attractive Models in Advertising. Journal of Advertising, 30, 1-12. https://doi.org/10.1080/00913367.2001.10673627

[15] Häfner, M. and Trampe, D. (2009) When Thinking Is Beneficial and When It Is Not: The Effects of Thin and Round Advertising Models. Journal of Consumer Psychology, 19, 619-628. https://doi.org/10.1016/j.jcps.2009.06.004

[16] Edell, J.A. and Staelin, R. (1983) The Information Processing of Pictures in Print Advertisements. Journal of Consumer Research, 10, 45-61. https://doi.org/10.1086/208944

[17] Miniard, P.W., Bhatla, S., Lord, K.R., Dickson, P.R. and Unnava, H.R. (1991) Picture-Based Persuasion Processes and the Moderating Role of Involvement. Journal of Consumer Research, 18, 92-107. https://doi.org/10.1086/209244

[18] Botta, R. (1999) Television Images and Adolescent Girls' Body Image Disturbance. Journal of Communication, 49, 22-41. https://doi.org/10.1111/j.1460-2466.1999.tb02791.x

[19] Jiang, Y. and Chen, H. (2016) The Relation between Women's Dressing Behavior and Body Self: Review and Prospect of Empirical Research. Chinese Journal of Applied Psychology, 22, 195-202.

[20] Tiggemann, M. and Zaccardo, M. (2015) "Exercise to Be Fit, Not Skinny": The Effect of Fitspiration Imagery on Women's Body Image. Body Image, 15, 61-67. 
https://doi.org/10.1016/j.bodyim.2015.06.003

[21] Kim, M. and Park, W. (2016) Who Is at Risk on Facebook? The Effects of Facebook News Feed Photographs on Female College Students' Appearance Satisfaction. The Social Science Journal, 53, 427-434. https://doi.org/10.1016/j.soscij.2016.08.007

[22] Ensher, E.A. and Murphy, S.E. (1997) Effects of Race, Gender, Perceived Similarity, and Contact on Mentor Relationships. Journal of Vocational Behavior, 50, 460-481. https://doi.org/10.1006/jvbe.1996.1547

[23] Racherla, P., Mandviwalla, M. and Connolly, D.J. (2012) Factors Affecting Consumers' Trust in Online Product Reviews. Journal of Consumer Behavior, 11, 94-104. https://doi.org/10.1002/cb.385

[24] Mussweiler, T. (2003) Comparison Processes in Social Judgment: Mechanisms and Consequences. Psychological Review, 110, 472-489. https://doi.org/10.1037/0033-295X.110.3.472

[25] Mussweiler, T., Rüter, K. and Epstude, K. (2004) The Ups and Downs of Social Comparison: Mechanisms of Assimilation and Contrast. Journal of Personality and Social Psychology, 87, 832-844. https://doi.org/10.1037/0022-3514.87.6.832

[26] Xing, S. and Yu, G. (2006) Social Comparison: Contrast Effect or Assimilation Effect? Advances in Psychological Science, 14, 944-949.

[27] Wan, L.C. and Wyer, R.S. (2015) Consumer Reactions to Attractive Service Providers: Approach or Avoid? Journal of Consumer Research, 42, 578-595.

https://doi.org/10.1093/jcr/ucv044

[28] Praxmarer, S. (2011) How a Presenter's Perceived Attractiveness Affects Persuasion for Attractiveness-Unrelated Products. International Journal of Advertising, 30, 839-865. https://doi.org/10.2501/IJA-30-5-839-865

[29] Cash, T.F., Fleming, E.C., Alindogan, J., Steadman, L. and Whitehead, A. (2002) Beyond Body Image as a Trait: The Development and Validation of the Body Image States Scale. The Journal of Treatment \& Prevention, 10, 103-113. https://doi.org/10.1080/10640260290081678

[30] Neese, W.T. and Taylor, R.D. (1994) Verbal Strategies for Indirect Comparative Advertising. Journal of Advertising Research, 34, 56-69.

[31] Batson, C.D., Lishner, D.A., Cook, J. and Sawyer, S. (2005) Similarity and Nurturance: Two Possible Sources of Empathy for Strangers. Basic and Applied Social Psychology, 27, 15-25. https://doi.org/10.1207/s15324834basp2701_2

[32] Liu, D. and Schaubel, D.E. (2007) Why Are You Telling Me This? An Examination into Negative Consumer Reviews on the Web. Journal of Interactive Marketing, 21, 76-94. https://doi.org/10.1002/dir.20090

[33] Williams, P. and Drolet, A. (2005) Age-Related Differences in Responses to Emotional Advertisements. Journal of Consumer Research, 32, 343-354. https://doi.org/10.1086/497545 